\title{
Higher Serum Levels of Free $\kappa$ plus $\lambda$ Immunoglobulin Light Chains Ameliorate Survival of Hemodialysis Patients
}

\author{
Florian Thilo $^{\mathrm{a}}$ Christina Caspari $^{\mathrm{a}} \quad$ Alexandra Scholze ${ }^{\mathrm{a}, \mathrm{b}} \quad$ Martin Tepel $^{\mathrm{a}, \mathrm{b}}$ \\ ${ }^{a}$ Med. Klinik Nephrologie, Charité Campus Benjamin Franklin, Berlin, Germany; ${ }^{b}$ Department of Nephrology, \\ Odense University Hospital, and Cardiovascular and Renal Research, Institute of Molecular Medicine, \\ University of Southern Denmark, Odense, Denmark
}

\section{Key Words}

Free light chains $\cdot$ Hemodialysis $\cdot$ Chronic kidney disease stage 5

\begin{abstract}
Background/Aims: Impaired immune function is common in patients with chronic renal failure. Now, we determined whether serum levels of free immunoglobulin light chains predict mortality in patients with chronic kidney disease stage 5 on hemodialysis. Methods: We performed a prospective cohort study of 160 hemodialysis patients with a median follow-up of 15 months (interquartile range, 3-44 months). Serum levels of free $\kappa$ and $\lambda$ immunoglobulin light chains were measured at the start of the study. The primary end point was mortality from any cause. Results: In survivors, median serum levels of free $\kappa$ plus $\lambda$ immunoglobulin light chains were significantly higher compared with nonsurvivors $(p<0.05)$. Survival was significantly longer in those patients who had serum levels of free $\kappa$ plus $\lambda$ immunoglobulin light chains above the median compared with patients with serum levels below the median of $210 \mathrm{mg} / \mathrm{l}\left(\chi^{2}=5.91\right.$; $p=0.015$ by log-rank, Mantel-Cox, test). We performed univariate and multivariate regression analysis showing that older age and lower serum levels of free $\kappa$ plus $\lambda$ immuno-
\end{abstract}

globulin light chains predicted mortality in hemodialysis patients. Conclusion: Higher serum levels of free $\kappa$ plus $\lambda$ immunoglobulin light chains ameliorate survival in hemodialysis patients.

Copyright $\odot 2011$ S. Karger AG, Basel

Plasma cells develop from stem cells in bone marrow. Plasma cells produce immunoglobulins, which consist of two identical heavy chains and light chains. There are two types of light chains: $\kappa$ and $\lambda$ light chains. In addition to the light chains as part of the immunoglobulins, low levels of free immunoglobulin light chains are produced in slight excess of heavy chains and thus circulate in the blood. Measurements of free immunoglobulin light chains have improved diagnosis and monitoring of the course of many monoclonal gammopathies. Measurements of the serum levels of free immunoglobulin light chains are now part of recommendations concerning the diagnosis of monoclonal gammopathies $[1,2]$.

Free $\kappa$ light chains are monomeric, while free $\lambda$ light chains are mainly dimeric. As a consequence of the lower molecular weight of the $\kappa$-monomers the glomerular filtration rate for $\kappa$ is three times as high as for $\lambda$ light chain dimers. Light chains are filtered by the kidney glomeruli

\section{KARGER}

Fax +41613061234 E-Mail karger@karger.ch www.karger.com
(C) 2011 S. Karger AG, Basel

$1420-4096 / 11 / 0345-0344 \$ 38.00 / 0$

Accessible online at:

www.karger.com/kbr
Dr. Martin Tepel

Department of Nephrology, Odense University Hospital, and Cardiovascular and Renal Research, Institute of Molecular Medicine, University of Southern Denmark Winslowparken 21.3, DK-5000 Odense C (Denmark)

E-Mailmtepel@health.sdu.dk 
and afterwards reabsorbed by the proximal tubuli mediated by megalin-cubulin receptor endocytosis and metabolized [3]. Only if the serum concentration of free light chains is greatly increased, the absorption maximum of the kidney is exceeded and free light chains are excreted by the urine. Due to reduced free light chain clearances, patients with chronic kidney disease have increased levels of serum free immunoglobulin light chains. Previous studies showed that the increased serum concentrations of free immunoglobulin light chains correlate with parameters of kidney function including creatinine and cystatin C $[3,4]$. Several factors have been established that predict mortality in hemodialysis patients $[5,6]$. However, currently the consequences of increased serum concentrations of free immunoglobulin light chains for life expectancy in patients with chronic kidney disease remain unknown. Therefore, we prospectively evaluated the role of the serum concentrations of free $\kappa$ and $\lambda$ immunoglobulin light chains as an independent predictor of mortality in 160 patients with chronic kidney disease stage 5 on hemodialysis.

\section{Subjects and Methods}

\section{Patients}

We prospectively studied 160 patients with chronic kidney disease stage 5 on hemodialysis treatment. All subjects gave written informed consent, and the study was approved by the local ethics committee. 112 were male and 48 were female, median age was 67 years (interquartile range $56-76$ years). Dialyses were performed using standardized techniques with bicarbonate-based dialysates and controlled ultrafiltration rate. Blood flow rates were $250-300 \mathrm{ml} / \mathrm{min}$, dialysate flow rates were $500 \mathrm{ml} / \mathrm{min}$, and dialysate conductivity was $135 \mathrm{mS} / \mathrm{cm}$. Patient dry weight was defined as the body weight below which the patient experienced hypotension or muscle cramps, and postural hypotension was clinically manifest. Patient history was assessed by trained personnel using medical records and a standardized questionnaire, and comprised personal history and previous history of cardiovascular disease, including coronary artery disease, angina pectoris and peripheral vascular and cerebrovascular disease. Blood pressure was measured before dialysis with a sphygmomanometer after 10 min of recumbency. Phases I and V of the Korotkoff sounds were taken as systolic and diastolic blood pressure, respectively. Pulse pressure was calculated as the difference between systolic and diastolic blood pressure. Blood samples were taken before the hemodialysis session. Kt/V values, i.e. the amount of plasma cleared of urea divided by the urea distribution volume, was measured according to the formula Kt/V $=-\ln (\mathrm{R}-0.03)+(4-3.5 \times$ $\mathrm{R}) \times \mathrm{UF} / \mathrm{W}$, where $\mathrm{R}=$ post-/pre-plasma urea nitrogen ratio, $\mathrm{UF}=$ ultrafiltrate volume (liters) removed, and $\mathrm{W}=$ postdialysis weight $(\mathrm{kg})$ [7]. To be included in the study, patients needed to have chronic kidney disease stage 5 and to be routinely dialyzed for 4-5 h three times weekly using biocompatible polysulfone low flux membrane (F8, Fresenius Medical Care; ultrafiltration coefficient, $7 \mathrm{ml} / \mathrm{h} / \mathrm{mm} \mathrm{Hg}$; surface area, $1.0 \mathrm{~m}^{2}$ ) with no dialyzer reuse. Patients were ambulatory and free of acute intercurrent illness. Both male and female patients were included. Patients who did not give written consent were excluded from the study. $\mathrm{Pa}-$ tients with known or already treated monoclonal gammopathies were excluded.

Measurement of Serum Free Immunoglobulin Light Chains

Serum levels of free $\kappa$ and $\lambda$ immunoglobulin light chains were measured by nephelometry as described [8]. We used a particleenhanced, high-specificity, homogenous immunoassay according to the recommendations of the manufacturer. The assay sensitivity was less than $1 \mathrm{mg} / \mathrm{l}$ [9]. The manufacturer of the immunoassay (Freelite ${ }^{\circledR}$; The Binding Site, Birmingham, UK) provided the assay for determination of serum levels of free $\kappa$ and $\lambda$ immunoglobulin light chains. The company had no role in the design of the study or the collection, analysis, or interpretation of the data or the writing of the manuscript. The authors vouch for the accuracy and completeness of the reported data.

\section{Statistics}

Data were expressed as the median and interquartile range. Statistical analyses were performed using GraphPad Prism 5.0 (GraphPad Software, San Diego, Calif., USA) or SPSS for Windows (version 15.0; SPSS, Chicago, Ill., USA). Data on free immunoglobulin light chains were analyzed using the D'AgostinoPearson normality test. Because data on free light chains did not show Gaussian distribution $(\mathrm{K} 2=234, \mathrm{p}<0.0001)$, data were transformed logarithmically. Between groups, comparisons were made using the nonparametric Mann-Whitney test. The relationships between serum concentrations of free $\kappa$ plus $\lambda$ immunoglobulin light chains and other variables were analyzed by nonparametric Spearman correlation. Categorical variables comprising gender $($ male $=1$, female $=2$ ) and diabetes (yes $=1$, no $=0$ ) were compared using Fisher's exact test. A p value less than 0.05 was taken to indicate statistical significance. All statistical tests were two sided.

The outcome event investigated was all-cause mortality. This outcome event was specified a priori. Survival curves (time-toevent analysis) were generated using the Kaplan-Meier product limit method and compared by the log-rank (Mantel-Cox) test. For the Kaplan-Meier analysis, the cohort was divided into two groups according to serum levels of free $\kappa$ plus $\lambda$ immunoglobulin concentrations above or below the median value.

The analysis used the unadjusted Cox proportional hazards analysis. Multivariate Cox proportional hazard analysis was then applied to determine the independence of the relationship of all covariates. Covariates were selected on the basis of prior research results, clinical experience and classical clinical performance measures, and included age, Kt/V urea value, gender, smoking, diabetes mellitus, previous cardiovascular disease and pulse pressure. In a stepwise forward regression analysis, variables with a $\mathrm{p}$ value less than 0.05 were retained. Adjusted relative risks were calculated as the antilogarithm of the $\beta$-coefficient of the Cox-proportional hazards regression analysis. The $95 \%$ confidence interval for the relative risk estimates was obtained using the antilogarithm $(\beta$ $\pm 1.96 \times$ standard error of $\beta$ ). Each significant predictor identified by that analysis was subsequently tested in a backward selection process with all covariates forced into the model. 
Table 1. Clinical and biochemical characteristics of 160 patients with chronic kidney disease stage 5 on hemodialysis

\begin{tabular}{lc}
\hline Characteristic & Median (interquartile range) \\
\hline Age, years & $67(56-76)$ \\
Male/female & $112 / 48$ \\
BMI & $24.1(20.9-26.5)$ \\
Duration of hemodialysis, months & $7(1-38)$ \\
Systolic blood pressure, mm Hg & $130(113-150)$ \\
Diastolic blood pressure, mm Hg & $69(57-80)$ \\
Pulse pressure, mm Hg & $61(50-71)$ \\
Hemoglobin, g/dl & $10.1(9.2-11.6)$ \\
Serum albumin, g/dl & $3.3(2.9-3.8)$ \\
Serum cholesterol, mg/dl & $154(129-186)$ \\
Serum triglyceride, mg/dl & $159(106-230)$ \\
$\kappa, \mathrm{mg} / \mathrm{l}$ & $107(64-182)$ \\
$\lambda, \mathrm{mg} / \mathrm{l}$ & $72(42-139)$ \\
$\kappa$ plus $\lambda, \mathrm{mg} / \mathrm{l}$ & $210(116-316)$ \\
\hline
\end{tabular}

$\kappa=$ Free $\kappa$ immunoglobulin light chains; $\lambda=$ free $\lambda$ immunoglobulin light chains.

\section{Results}

We investigated the outcome of patients with chronic kidney disease stage 5 on hemodialysis treatment according to the serum concentrations of free $\kappa$ and $\lambda$ immunoglobulin light chains in a prospective cohort study. A total of 160 patients with chronic kidney disease stage 5 (112 males, 48 females; median age, 67 years; interquartile range, 56-76 years) who were receiving hemodialysis for at least 1 month were enrolled in the study. The cause of end-stage renal disease was diabetic nephropathy in 29 cases (18\%), nephrosclerosis in 62 cases $(39 \%)$, chronic glomerulonephritis in 17 cases (11\%), polycystic kidney disease in 4 cases (3\%), and other/unknown in 48 cases (30\%). Angiotensin-converting enzyme inhibitors were prescribed in 47 cases (29\%), beta-blockers in 83 cases (52\%), calcium channel blockers in 48 cases (30\%) and erythropoietin therapy in 95 cases (59\%). The median duration of hemodialysis at inclusion was 7 months (interquartile range, 1-38 months). 144 previous cardiovascular events were reported in 160 patients (90\%), including a history of coronary artery disease (72 cases, $45 \%)$, peripheral vascular disease (35 cases, 22\%) and cerebrovascular disease (27 cases, $17 \%$ ). Patients with known or already treated monoclonal gammopathies were excluded from the study. The clinical and biochemical characteristics of the patients are summarized in table 1. Median $\mathrm{Kt} / \mathrm{V}$ was 1.1 (interquartile range, 1.0-1.2).
In 160 patients, the median serum level of free $\kappa$ light chains was $107 \mathrm{mg} / \mathrm{l}$ (interquartile range, 64-182 mg/l), and for free $\lambda$ light chains it was $72 \mathrm{mg} / \mathrm{l}$ (interquartile range, $42-139 \mathrm{mg} / \mathrm{l}$ ). The median serum level of free $\mathrm{\kappa}$ plus $\lambda$ immunoglobulin light chains was $210 \mathrm{mg} / \mathrm{l}$ (interquartile range, $116-316 \mathrm{mg} / \mathrm{l})$. Next, we assessed factors that may influence serum levels of free immunoglobulin light chain in hemodialysis patients. We found that serum levels of free $\kappa$ plus $\lambda$ immunoglobulin light chains were significantly correlated with age (Spearman $\mathrm{r}=$ $-0.17 ; 95 \% \mathrm{CI}-0.32$ to $-0.01 ; \mathrm{p}<0.05$ ) but not with $\mathrm{Kt} / \mathrm{V}$ (Spearman $\mathrm{r}=0.07 ; 95 \% \mathrm{CI}-0.10$ to 0.23 ; $\mathrm{p}=0.42$ ) or pulse pressure (Spearman $\mathrm{r}=0.10 ; 95 \% \mathrm{CI}-0.07$ to 0.27 ; $\mathrm{p}=0.22$ ).

Now, we evaluated whether the serum levels of free $\kappa$ and $\lambda$ immunoglobulin light chains predicted mortality in hemodialysis patients. Data on mortality were obtained for the entire cohort. During follow-up (median, 15 months; interquartile range, 3-44 months), 87 patients (54\%) died. The cause of death was cardiovascular disease in 44 patients (51\%), infections in 31 patients (36\%), cancer in 9 patients $(10 \%)$, and other or unknown in 3 patients (3\%). Nine patients (6\%) underwent kidney transplantation during follow-up. Those patients were censored on the day of transplantation. In survivors, serum levels of free $\kappa$ plus $\lambda$ immunoglobulin light chains were significantly higher (median, $230 \mathrm{mg} / \mathrm{l}$; interquartile range, $141-369 \mathrm{mg} / \mathrm{l} ; \mathrm{n}=73$ ) compared with nonsurvivors (median, $183 \mathrm{mg} / \mathrm{l}$; interquartile range, $86-293 \mathrm{mg} / \mathrm{l}$; $\mathrm{n}=87 ; \mathrm{p}<0.05)$. These data indicated that lower serum levels of $\kappa$ plus $\lambda$ free immunoglobulin light chains were associated with increased mortality.

Figure la shows the probabilities of survival of patients with chronic kidney disease stage 5 on hemodialysis according to the serum level of free $\kappa$ plus $\lambda$ immunoglobulin light chains. Survival was significantly longer in patients with serum levels of free $\kappa$ plus $\lambda$ immunoglobulin light chains above the median value (i.e. above $210 \mathrm{mg} / \mathrm{l}$ ) compared to patients with serum levels below the median $\left(\chi^{2}=5.91 ; \mathrm{p}=0.015\right.$ by log-rank, Mantel-Cox, test). Median survival in the group with serum levels of free $\kappa$ plus $\lambda$ immunoglobulin light chains above $210 \mathrm{mg} / \mathrm{l}$ was 43 months, whereas median survival in the group with serum levels below $210 \mathrm{mg} / \mathrm{l}$ was 27 months. As indicated in figure $1 b, c$, patients with $\kappa$ immunoglobulin light chains above median or $\lambda$ immunoglobulin light chains above median showed marginally significant improved survival, $\mathrm{p}=0.066$ or $\mathrm{p}=0.054$ by log-rank (Mantel-Cox) test, respectively. 


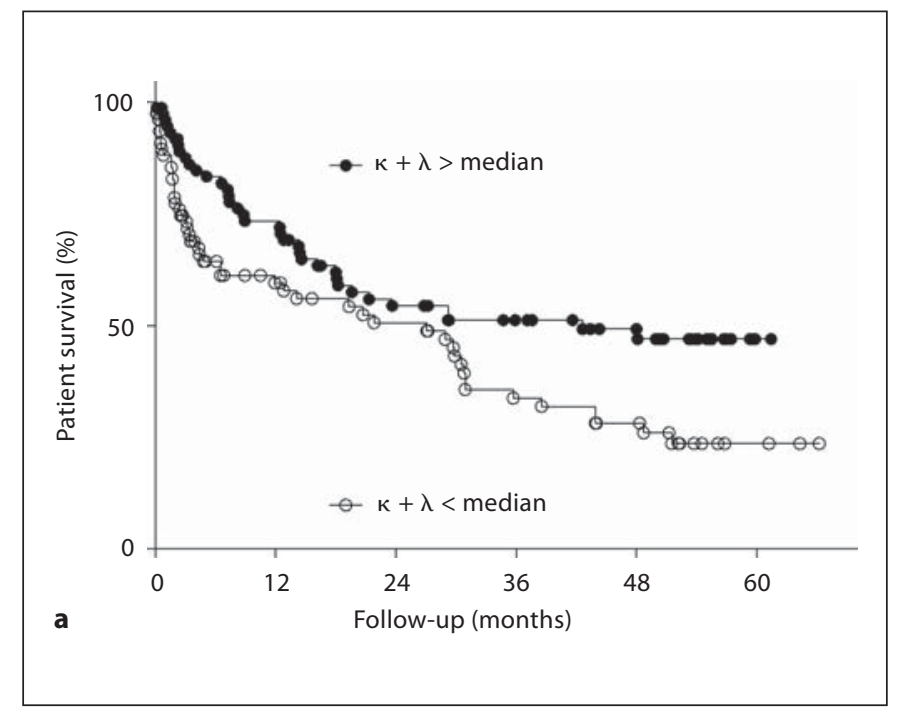

Fig. 1. Kaplan-Meier survival curve for all-cause mortality in patients with chronic kidney disease stage 5 on hemodialysis according to free $\kappa$ and $\lambda$ immunoglobulin light chain serum levels. a Patients with serum values of free $\kappa$ plus $\lambda$ immunoglobulin light chains above median show significantly improved survival. $\mathrm{p}=0.015$ by log-rank (Mantel-Cox) test. Patients with $\kappa$ immunoglobulin light chains above median (b) or $\lambda$ immunoglobulin light chains above median (c) showed marginally significant improved survival. $\mathrm{p}=0.066$ or $\mathrm{p}=0.054$ by log-rank (Mantel-Cox) test, respectively.

The unadjusted Cox proportional hazards analysis identified age and the logarithmically transformed serum levels of free $\kappa$ plus $\lambda$ immunoglobulin light chains as significantly associated with mortality (table 2). Next, we used adjusted Cox proportional hazards analysis of all-cause mortality. The multivariate analysis showed that age $(\mathrm{p}<0.001)$ and the logarithmically transformed serum levels of free $\kappa$ plus $\lambda$ immunoglobulin light chains $(\mathrm{p}=0.036)$ significantly predicted mortality in patients with chronic kidney disease stage 5 on hemodialysis (table 3). Multivariate analysis confirmed that both older age and lower logarithmically transformed serum levels of free $\kappa$ plus $\lambda$ immunoglobulin light chains were associated with increased mortality.

Free Light Chains and Survival
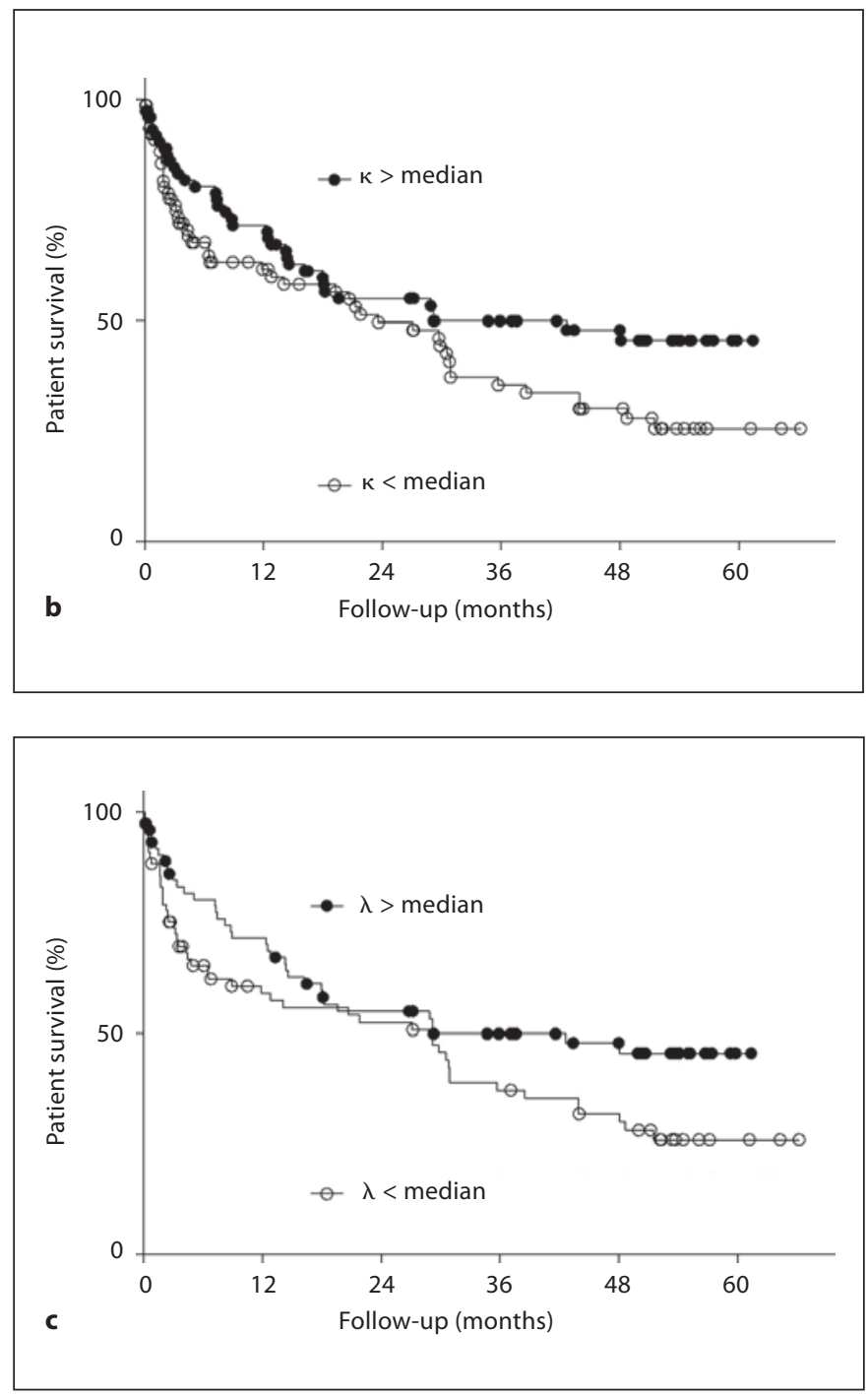

\section{Discussion}

The purpose of this prospective cohort study of 160 patients was to assess whether serum levels of free immunoglobulin light chains predict mortality in patients with chronic kidney disease stage 5 on hemodialysis. This study is the first to show that serum levels of free $\kappa$ plus $\lambda$ immunoglobulin light chains significantly predicted mortality in these patients. Univariate as well as multivariate regression analysis showed that older age and lower serum levels of free $\kappa$ plus $\lambda$ immunoglobulin light chains predict mortality in hemodialysis patients. It should be noted that patients with known or already treated monoclonal gammopathies were excluded from the present study.

Kidney Blood Press Res 2011;34:344-349 
Table 2. Univariate Cox proportional hazards analysis of allcause mortality in patients with chronic kidney disease stage 5 on hemodialysis treatment

\begin{tabular}{|c|c|c|c|}
\hline Variable & $\begin{array}{l}\text { Wald } \\
\text { Z value }\end{array}$ & $\mathrm{p}$ & RR $(95 \%$ CI $)$ \\
\hline Age & 26.82 & 0.000 & $1.065(1.040-1.091)$ \\
\hline $\log (\kappa$ plus $\lambda)$ & 4.383 & 0.036 & $0.447(0.210-0.950)$ \\
\hline \multicolumn{4}{|l|}{ Gender } \\
\hline$(1=$ male $; 2=$ female $)$ & 1.728 & 0.189 & $0.687(0.392-1.203)$ \\
\hline $\mathrm{Kt} / \mathrm{V}$ & 0.022 & 0.882 & $0.916(0.289-2.909)$ \\
\hline Smoking $(1=$ yes; $0=$ no $)$ & 0.677 & 0.411 & $0.781(0.433-1.408)$ \\
\hline Diabetes $(1=$ yes; $0=$ no $)$ & 0.765 & 0.382 & $1.274(0.740-2.194)$ \\
\hline $\operatorname{CVD}(1=$ yes; $0=$ no $)$ & 0.728 & 0.393 & $0.798(0.474-1.341)$ \\
\hline Pulse pressure & 1.796 & 0.180 & $0.991(0.979-1.004)$ \\
\hline
\end{tabular}

$\log (\kappa$ plus $\lambda$ ) indicates the logarithm of serum levels of free $\kappa$ plus $\lambda$ immunoglobulin light chains. $\mathrm{Kt} / \mathrm{V}=$ Dialysis dose. $\mathrm{CVD}$ indicates history of cardiovascular disease (events).

An immunoassay which detects free light chains has been available since 2001 [8]. Hutchison et al. [3] assessed free light chains in patients with chronic kidney disease of diverse etiology. They showed a positive correlation between serum levels of free $\kappa$ and $\lambda$ immunoglobulin light chains and renal impairment parameters including creatinine and cystatin C. In patients with chronic kidney failure, a gradual increase in the median serum free light chain levels was observed. It was noticed that patients who were already on a dialysis schedule showed significantly higher free light chain concentrations than patients classified as CKD stage 5 but not yet on hemodialysis treatment.

Why do hemodialysis patients with higher serum levels of free $\kappa$ plus $\lambda$ immunoglobulin light chains show improved survival? A recent study by Lorenzen et al. [10] indicated that several traditional risk factors did not affect incident cardiovascular events including death in hemodialysis patients. Therefore, other factors, including free light chains, may be more important for the survival of hemodialysis patients. Several mechanisms may contribute to this finding. First, reduced serum levels of free $\kappa$ and $\lambda$ immunoglobulin light chains may indicate global impairment of bone marrow function probably due to long-standing uremia. Several groups established impaired immunoglobulin production by B cells from hemodialysis patients $[11,12]$. Impaired immunoglobulin production by $\mathrm{B}$ cells has been associated with secondary hyperparathyroidism in hemodialysis patients $[11,12]$.
Table 3. Adjusted Cox proportional hazards analysis of all-cause mortality in patients with chronic kidney disease stage 5 on hemodialysis

\begin{tabular}{lccl}
\hline Variable & Wald Z value & \multicolumn{1}{c}{$p$} & RR (95\% CI) \\
\hline Age & 28.241 & $<0.001$ & $1.059(1.037-1.081)$ \\
$\log (\kappa$ plus $\lambda)$ & 4.548 & 0.033 & $0.451(0.217-0.938)$ \\
\hline
\end{tabular}

Therefore, it is likely that higher levels of free $\kappa$ and $\lambda$ immunoglobulin light chains may reflect lower uremic toxicity and thus improved survival. In turn, long-standing increased uremia may be monitored by reduced immunoglobulin light chain levels leading to increased mortality. Second, Cohen et al. [13] showed that $\kappa$ and $\lambda$ immunoglobulin light chains increased the percentage of viable polymorphonuclear leukocytes by inhibiting apoptosis in a concentration-dependent manner. The increased number of viable polymorphonuclear leukocytes may be beneficial for combating bacterial infections. It is well known that infections are a leading cause of mortality in hemodialysis patients. Third, immunoglobulin light chains have been reported to activate mast cells [14]. Recent studies revealed the potential of mast cells to produce prompt inflammatory responses and to fight infections in the early stages of sepsis [15]. Therefore, enforcing mast cell activation by higher $\kappa$ and $\lambda$ immunoglobulin light chain levels may facilitate relief from bacterial infections. Further experimental and clinical studies are needed to clarify the role of free light chains in the outcome of hemodialysis patients.

In conclusion, higher serum levels of free $\kappa$ plus $\lambda$ immunoglobulin light chains improve survival in hemodialysis patients.

\section{Acknowledgement}

The manufacturer of the immunoassay (Freelite; The Binding Site, Birmingham, UK) provided the immunoassay for determination of serum levels of free $\kappa$ and $\lambda$ immunoglobulin light chains.

\section{Disclosure Statement}

The authors declare that they have no competing financial interests. There is no conflict of interest. 


\section{References}

1 Martin W, Abraham R, Shanafelt T, Clark RJ, Bone N, Geyer SM, Katzmann JA, Bradwell A, Kay NE, Witzig TE: Serum-free light chain - a new biomarker for patients with Bcell non-Hodgkin lymphoma and chronic lymphocytic leukemia. Transl Res 2007;149: 231-235.

2 Durie BG, Harousseau JL, Miguel JS, Bladé J, Barlogie B, Anderson K, Gertz M, Dimopoulos M, Westin J, Sonneveld P, Ludwig H, Gahrton G, Beksac M, Crowley J, Belch A, Boccadaro M, Cavo M, Turesson I, Joshua D, Vesole D, Kyle R, Alexanian R, Tricot G, Attal M, Merlini G, Powles R, Richardson P, Shimizu K, Tosi P, Morgan G, Rajkumar SV; International Myeloma Working Group: International uniform response criteria for multiple myeloma. Leukemia 2006;20:14671473.

3 Hutchison CA, Harding S, Hewins P, Mead GP, Townsend J, Bradwell AR, Cockwell P: Quantitative assessment of serum and urinary polyclonal free light chains in patients with chronic kidney disease. Clin J Am Soc Nephrol 2008;3:1684-1690.

4 Rolinski B, Hammer F, Scherberich J: Serum concentrations of kappa and lambda free light chains in chronic renal failure. Clin Chem Lab Med 2006;44:A160.
5 Miller JE, Kovesdy CP, Norris KC, Mehrotra R, Nissenson AR, Kopple JD, Kalantar-Zadeh K: Association of cumulatively low or high serum calcium levels with mortality in long-term hemodialysis patients. Am J Nephrol 2010;32:403-413.

6 Scholze A, Thies C, Cheikhalfraj M, Wittstock A, Pommer W, Zidek W, Tepel M: Mortality risk in hemodialysis patients with increased arterial stiffness is reduced by attainment of classical clinical performance measures. Am J Nephrol 2009;29:598-606.

7 Daugirdas JT: Second generation logarithmic estimates of single-pool variable volume $\mathrm{Kt} / \mathrm{V}$ : an analysis of error. J Am Soc Nephrol 1993;4:1205-1213.

$\checkmark 8$ Bradwell AR, Carr-Smith HD, Mead GP, Tang LX, Showell PJ, Drayson MT, Drew R: Highly sensitive, automated immunoassay for immunoglobulin free light chains in serum and urine. Clin Chem 2001;47:673-680.

$\checkmark 9$ Katzmann JA, Clark RJ, Abraham RS, Bryant S, Lymp JF, Bradwell AR, Kyle RA: Serum reference intervals and diagnostic ranges for free kappa and free lambda immunoglobulin light chains: relative sensitivity for detection of monoclonal light chains. Clin Chem 2002; 48:1437-1444
10 Lorenzen JM, David S, Richter A, de Groot K, Kielstein JT, Haller H, Thum T, Fliser D: TLR-4+ peripheral blood monocytes and cardiovascular events in patients with chronic kidney disease - a prospective follow-up study. Nephrol Dial Transplant 2011; 26:1421-1424.

11 Smogorzewski M, Massry SG: Defects in Bcell function and metabolism in uremia: role of parathyroid hormone. Kidney Int Suppl 2001;78:S186-S189.

12 Alexiewicz JM, Klinger M, Pitts TO, Gaciong Z, Linker-Israeli M, Massry SG: Parathyroid hormone inhibits B cell proliferation: implications in chronic renal failure. J Am Soc Nephrol 1990;1:236-244.

13 Cohen G, Rudnicki M, Deicher R, Hörl WH: Immunoglobulin light chains modulate polymorphonuclear leucocyte apoptosis. Eur J Clin Invest 2003;33:669-676.

14 Redegeld FA, van der Heijden MW, Kool M, Heijdra BM, Garssen J, Kraneveld AD, Van Loveren H, Roholl P, Saito T, Verbeek JS, Claassens J, Koster AS, Nijkamp FP: Immunoglobulin-free light chains elicit immediate hypersensitivity-like responses. Nat Med 2002;8:694-701.

15 Echtenacher B, Männel DN, Hültner L: Critical protective role of mast cells in a model of acute septic peritonitis. Nature 1996;381:7577. 